\title{
Extracorporeal membrane oxygenation as a bridge to lung transplantation: A single-center experience in the present era
}

\author{
Emily M. Todd, CCP, ${ }^{\mathrm{a}}$ Sreeja Biswas Roy, MBBS, ${ }^{\mathrm{b}}$ A. Samad Hashimi, MD, ${ }^{\mathrm{c}}$ Rosemarie Serrone, MD, ${ }^{\mathrm{d}}$ \\ Roshan Panchanathan, BS, ${ }^{\mathrm{e}}$ Paul Kang, MPH, ${ }^{\mathrm{f}}$ Katherine E. Varsch, RN, MSN, CCTC, ${ }^{\mathrm{g}}$ \\ Barry E. Steinbock, BS, ${ }^{\mathrm{a}}$ Jasmine Huang, MD, ${ }^{\mathrm{c}}$ Ashraf Omar, MD, ${ }^{\mathrm{h}}$ Vipul Patel, MD, ${ }^{\mathrm{h}}$ Rajat Walia, MD, \\ Michael A. Smith, MD, ${ }^{c}$ and Ross M. Bremner, MD, $\mathrm{PhD}^{\mathrm{c}}$
}

\section{ABSTRACT}

Objective: Extracorporeal membrane oxygenation has been used as a bridge to lung transplantation in patients with rapid pulmonary function deterioration. The reported success of this modality and perioperative and functional outcomes are varied.

Methods: We retrospectively reviewed all patients who underwent lung transplantation at our institution over 1 year (January 1, 2015, to December 31, 2015). Patients were divided into 2 groups depending on whether they required extracorporeal membrane oxygenation support as a bridge to transplant; preoperative characteristics, lung transplantation outcomes, and survival were compared between groups.

Results: Of the 93 patients, $12(13 \%)$ received bridge to transplant, and $81(87 \%)$ did not. Patients receiving bridge to transplant were younger, had higher lung allocation scores, had lower functional status, and were more often on mechanical ventilation at listing. Most patients who received bridge to transplant $(\mathrm{n}=10$, $83.3 \%$ ) had pulmonary fibrosis. Mean pretransplant extracorporeal membrane oxygenation support was 103.6 hours in duration (range, 16-395 hours). All patients who received bridge to transplant were decannulated immediately after lung transplantation but were more likely to return to the operating room for secondary chest closure or rethoracotomy. Grade 3 primary graft dysfunction within 72 hours was similar between groups. Lung transplantation success and hospital discharge were $100 \%$ in the bridge to transplant group; however, these patients experienced longer hospital stays and higher rates of discharge to acute rehabilitation. The 1-year survival was $100 \%$ in the bridge to transplant group and $91 \%$ in the non-bridge to transplant group (log-rank, $P=.24)$. The 1-year functional status was excellent in both groups.

Conclusions: Extracorporeal membrane oxygenation can be used to safely bridge high-acuity patients with end-stage lung disease to lung transplantation with good 30-day, 90-day, and 1-year survival and excellent 1-year functional status. Longterm outcomes are being studied. (J Thorac Cardiovasc Surg 2017;154:1798-1809)

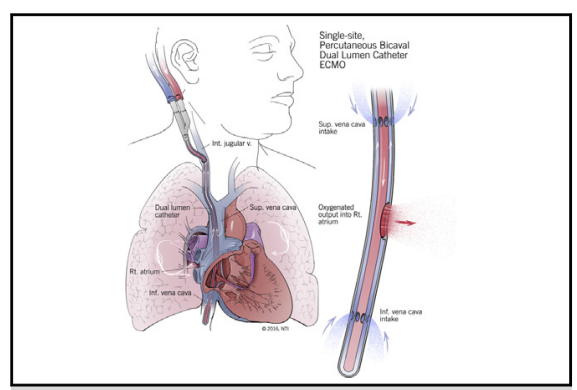

Artist's depiction of W ECMO dual-lumen Avalon cannula. Used with permission from Norton Thoracic Institute, Phoenix, Arizona.

\section{Central Message}

ECMO can be safely used as a bridge to LTx with high success rates and good short-term survival in select high-acuity patients with end-stage lung disease.

\section{Perspective}

ECMO can be used as bridge therapy in select critically ill patients who experience acute deterioration while awaiting LTx. Good shortterm outcomes regarding primary graft dysfunction rates, 1-year survival, and 1-year functional status can be achieved in select high-acuity patients.

See Editorial Commentary page 1810.

See Editorial page 1796.
Mechanical ventilation is the traditional method of respiratory support for patients with end-stage lung disease awaiting lung transplantation (LTx), but it is not sufficient for all

From the Departments of ${ }^{\mathrm{b}}$ Research Grants and ${ }^{\mathrm{g}}$ Lung Transplantation, Divisions of ${ }^{\mathrm{c}}$ Thoracic Surgery, and ${ }^{\mathrm{h}}$ Pulmonology, Norton Thoracic Institute, ${ }^{\mathrm{a}}$ Perfusion Department, ${ }^{\mathrm{d}}$ Department of Surgery, St. Joseph's Hospital and Medical Center; ${ }^{\mathrm{e}}$ University of Arizona College of Medicine, University of Arizona; and ${ }^{\mathrm{f}}$ University of Arizona College of Public Health, University of Arizona, Phoenix, Ariz. Institutional Review Board Approval Number: PHX-16-0125-71-18.

Read at the 42nd Annual Meeting of The Western Thoracic Surgical Association, Waikoloa, Hawaii, June 22-25, 2016. patients $^{1-4}$ and is associated with potentially devastating complications, such as ventilator-acquired pneumonia or ventilator-induced lung injury. Extracorporeal membrane

Received for publication June 21, 2016; revisions received April 3, 2017; accepted for publication June 27, 2017.

Address for reprints: Ross M. Bremner, MD, PhD, Norton Thoracic Institute, St Joseph's Hospital and Medical Center, 500 W. Thomas Rd, Ste 500, Phoenix, AZ 85013 (E-mail: Ross.Bremner@dignityhealth.org). 0022-5223/\$36.00

Copyright (C) 2017 Published by Elsevier Inc. on behalf of The American Association for Thoracic Surgery

http://dx.doi.org/10.1016/j.jtcvs.2017.06.063 

Abbreviations and Acronyms
AT = antithrombin
BTT = bridge to transplantation
$\mathrm{CPB}=$ cardiopulmonary bypass
DVT $=$ deep vein thrombosis
ECMO $=$ extracorporeal membrane oxygenation
LAS = lung allocation score
LTx = lung transplantation
UNOS $=$ United Network for Organ Sharing
$\mathrm{VA}=$ venoarterial
$\mathrm{VV}=$ venovenous

Scanning this QR code will take you to a supplemental video for the article.

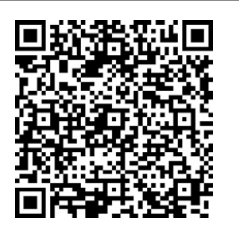

oxygenation (ECMO) is an alternative to mechanical ventilation that can provide respiratory support as a bridge therapy while a patient awaits a suitable donor for LTx. ${ }^{5}$ This technology and the experience levels of those operating it have evolved over the past few decades, and several centers now use ECMO as a bridge to transplantation (BTT). ${ }^{6-11}$ LTx outcomes after ECMO BTT vary on the basis of institutional practices. ${ }^{9}$ Although survival in patients who receive ECMO BTT has been reported to be lower than in non-BTT transplant recipients, ${ }^{1,12}$ the risks are not prohibitive. ${ }^{13}$ As the number and overall survival of patients receiving ECMO and undergoing LTx continue to increase, ${ }^{14}$ several centers have achieved better ECMO BTT survival that is comparable to that of patients without BTT. ${ }^{6,7}$ However, most centers are selective in using this approach, and many will use ECMO BTT only for patients who are already listed for LTx and who have good potential for rehabilitation. ${ }^{8,11}$ Nationwide registries have reported ECMO BTT to be more successful at highvolume LTx centers in the recent era, ${ }^{14,15}$ and ECMO deployment algorithms have been implemented with some success.

The 2005 implementation of the lung allocation score (LAS) system led to a dramatic increase in the proportion and number of transplants in high-acuity patients, ${ }^{16}$ including those on life support with ECMO or mechanical ventilation. The post-LAS era has seen decreasing numbers of waitlist deaths and increasing numbers of annual LTx procedures. ${ }^{17}$ However, patients with fibrotic lung disease often experience acute deterioration while awaiting LTx, and this deterioration necessitates hospitalization and respiratory support, sometimes in the form of ECMO.
In this study, we retrospectively reviewed the outcomes of all patients who underwent LTx at our high-volume institution over a single calendar year, just after the implementation of a comprehensive, multidisciplinary ECMO program. We compared the outcomes of all patients who received ECMO BTT during the study period with those of patients who did not receive BTT during the same period and compared the outcomes of patients who received ECMO BTT after our program initiation with the outcomes of patients who received ECMO BTT before this program began.

\section{MATERIALS AND METHODS Study Design}

This study was approved by the Institutional Review Board at St Joseph's Hospital and Medical Center in Phoenix, Arizona. We retrospectively reviewed all patients who underwent LTx at our institution over a single calendar year (January 1, 2015, to December 31, 2015), evaluating patients who received ECMO BTT after implementation of a comprehensive ECMO program. We compared the outcomes of patients who received ECMO BTT with those who did not and compared those who received ECMO BTT with those who received ECMO BTT during the 2011 to 2014 calendar years (ie, before the implementation of our dedicated ECMO program).

We analyzed reasons for ECMO implementation; duration of pre-LTx ECMO; procedure details; survival to transplant for patients who received ECMO BTT bridged with "intent to transplant"; post-LTx outcomes, including length of stay; post-LTx survival at 30 days, 90 days, and 1 year; and functional status at 1 year post-LTx. We also compared rates of delirium (defined according to the American Psychiatric Institution's Diagnostic and Statistical Manual, 5th Edition, Diagnostic and Statistical Manual of Mental Disorders, Fifth Edition) and critical illness myopathy (diagnosed by generalized muscle weakness or failure to wean from ventilator ${ }^{18}$ ) between groups. We compared parameters between those who received ECMO BTT and those who did not during the study period. We also identified a historical ECMO BTT cohort, which included all ECMO BTT cases before 2015 at our institution. The historical cohort was compared with the 2015 ECMO BTT cohort for differences in baseline characteristics, success of BTT, and survival.

Our multidisciplinary ECMO program was established in January 2015 after 3 main phases: physician and staff education, upgrades to technology, and clarification of communication. Our physicians and perfusionists attended a course held by the Extracorporeal Life Support Organization and attended a local education program that involved respiratory therapists and nurses from the intensive care unit. Our institution acquired a new ECMO circuit (Cardiohelp, Maquet Cardiovascular LLC, Wayne, NJ) and transitioned to using a dual-lumen venovenous (VV) cannula (Avalon Elite, Maquet Cardiovascular LLC). Our communication systems were vastly improved after making clear the responsibilities of various practitioners and delineating a clear communication pathway between 2 dedicated perfusionists and the on-call ECMO physician.

\section{Extracorporeal Membrane Oxygenation Indications and Institutional Practice}

At our institution, the decision to place any patient on ECMO as BTT is made by the ECMO team and is based on speed of deterioration and need for further oxygenation or ventilation despite maximum medical therapy. Our multidisciplinary team comprises LTx pulmonologists and surgeons, perfusionists, pharmacists, a psychiatrist, physical therapists, respiratory therapists, and nurses trained in adult ECMO. The most important factors we consider before placing a transplant candidate on ECMO BTT are 
physiologic age less than 65 years, ambulatory functional status before deterioration, no other organ dysfunction, and good potential for rehabilitation. Perfusionists have been designated as point-persons and are responsible for overseeing the ECMO program, including implementing and communicating new policies and procedures in collaboration with the surgical and medical directors of the program. Perfusionists are responsible for maintaining an ongoing education program, attending regular multidisciplinary meetings, and rounding at least twice each day on any patient on ECMO. When instability occurs with a patient for any reason, the perfusionist remains at the bedside.

\section{Procedure}

If circulatory support is not required, we prefer to place patients on VV ECMO using the dual-lumen VV catheter (Avalon Elite, Figure 1). If circulatory support is needed, as was the case for 1 patient in this study, venoarterial (VA) cannulation is used. Ideally, the patient is in the operating room for this procedure, which ensures that both transesophageal echocardiogram and fluoroscopy are available. The jugular vein is accessed, and a guidewire is passed into the inferior vena cava (Video 1). Care must be taken to ensure that the guidewire does not pass into the right ventricle, the coronary sinus, or 1 of the hepatic veins. These structures generally can be avoided using fluoroscopy, but transesophageal echocardiography can visualize critical anatomy. The tract is dilated, and the dual-lumen cannula is positioned so that the distal port is in the inferior vena cava and the outflow cannula, which carries oxygenated blood, is directed into the right ventricle. The cannula must be well secured (usually after removal of the shoulder roll) to avoid movement or displacement once correct placement has been confirmed.

In this study, patients were maintained on VV ECMO during LTx unless hemodynamic support was compromised, in which case the patient was converted to cardiopulmonary bypass (CPB) for the implantation procedure. Conversion to $\mathrm{CPB}$ was achieved by first cannulating the aorta and attaching the arterial line to the CPB system. The Avalon cannula was converted to venous drainage by attaching a $\mathrm{Y}$ connector to the inlet and outlet port of the Avalon cannula in a sterile fashion. The other end of the $\mathrm{Y}$ was then attached to the venous line of the CPB system.

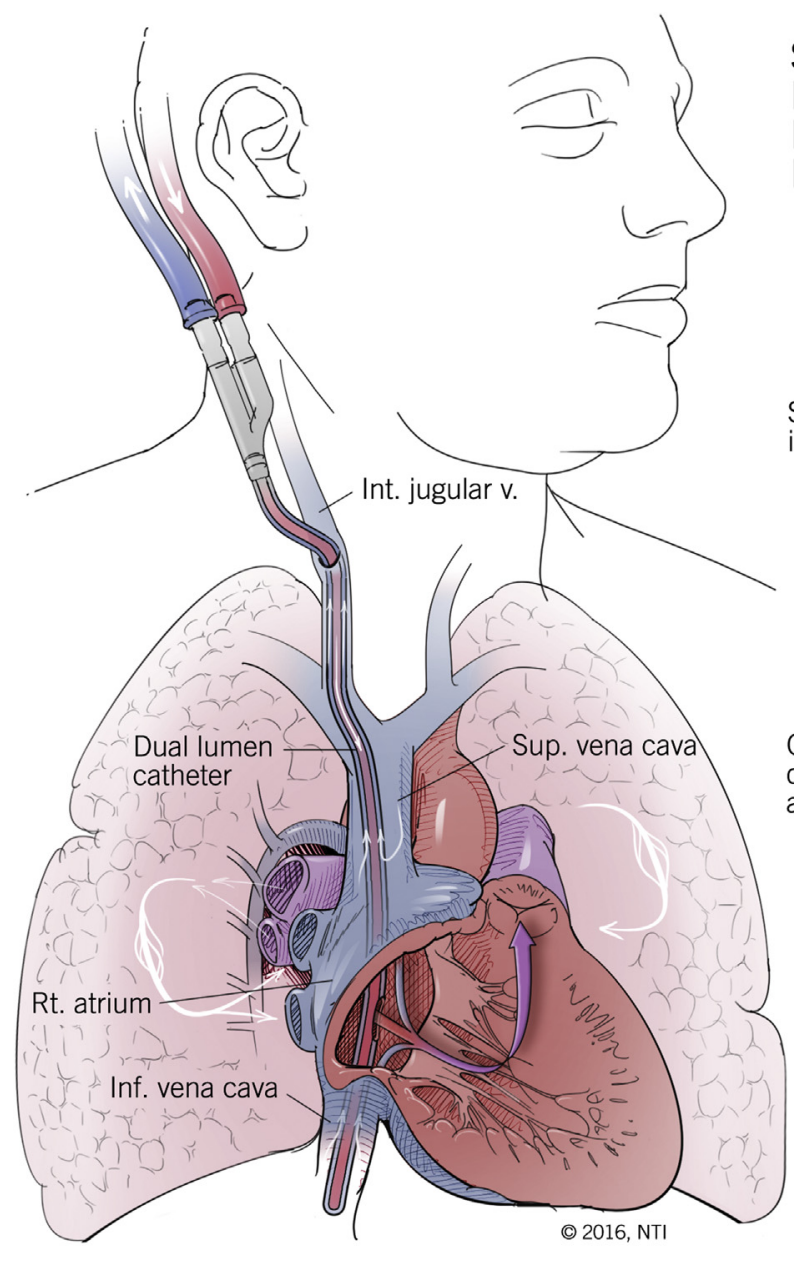

\section{Single-site, Percutaneous Bicaval Dual Lumen Catheter ECMO}

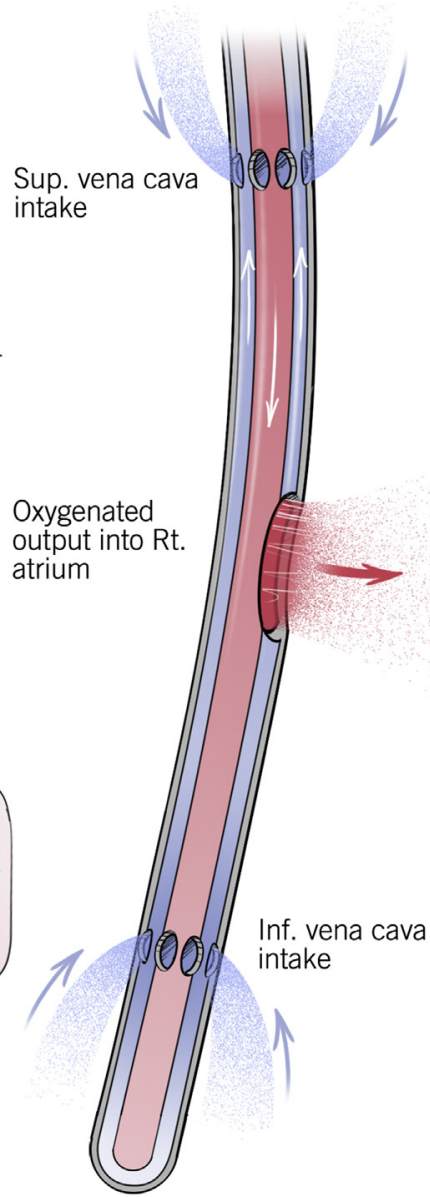

FIGURE 1. Artist's depiction of VV ECMO dual-lumen Avalon cannula (Maquet, Rastatt, Germany). ECMO, Extracorporeal membrane oxygenation. Used with permission from Norton Thoracic Institute, Phoenix, Arizona. 


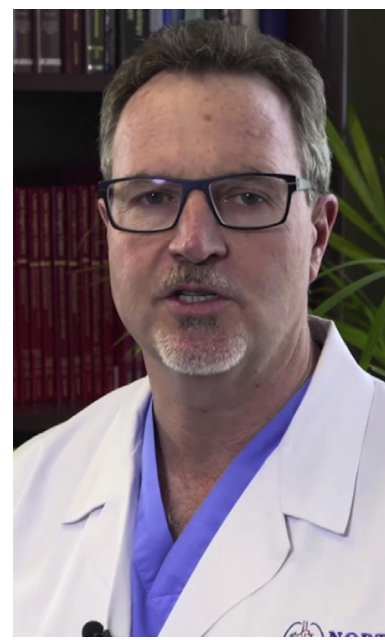

VIDEO 1. Video describing the role of ECMO as a BTT and a short video of a cannulation for ECMO. Used with permission from Norton Thoracic Institute, Phoenix, Arizona. Video available at: http://www.jtcvsonline. org/article/S0022-5223(17)31579-9/fulltext.

\section{Statistical Analysis}

Demographic and clinical characteristics were assessed using medians and interquartile ranges for continuous variables. Categoric variables were analyzed using frequencies and percentages. All continuous variables were studied using the Shapiro-Wilk Test for normality and assessed graphically. Because of the non-normal distribution of the continuous variables and the small sample size, the Wilcoxon rank-sum and Fisher exact tests were used to compare continuous and categoric variables, respectively. Probabilities of survival were estimated using Kaplan-Meier for the ECMO BTT and non-BTT groups. In addition, survival probabilities were estimated for the historical ECMO BTT and present ECMO BTT groups. The log-rank test was implemented to observe differences in probabilities of survival between ECMO BTT and non-BTT, as well as between the historical BTT and present ECMO BTT groups. All $P$ values were 2-sided. Statistical analysis was performed using Stata 2015, Release 14 (StataCorp LP, College Station, Tex).

\section{RESULTS}

Of the 93 patients who underwent LTx between January 1, 2015, and December 31, 2015, $12(13 \%)$ were bridged to transplant with ECMO (ie, the ECMO BTT group) and 81 $(87 \%)$ underwent LTx without ECMO BTT (ie, the nonBTT group). Eleven of the 12 patients receiving ECMO BTT were placed on ECMO after acute respiratory failure with hypoxia, hypercarbia, or both. The remaining patient was placed on ECMO after a brief period of cardiac arrest; emergency VA ECMO was initiated at the bedside.

Clinical characteristics and comparisons between the baseline characteristics of patients who received and did not receive ECMO BTT are summarized in Table 1. Patients who received ECMO BTT were younger $(P=.02)$, had higher LAS $(P<.001)$, had lower functional status $(P<.001)$, and were more likely to be on ventilator support at the time of listing for LTx $(P<.001)$. A total of 10 of 12 patients who received ECMO BTT $(83.3 \%)$ were categorized in the United Network for Organ Sharing (UNOS)
Group $\mathrm{D}^{19}$; just 46 of 81 patients who did not receive ECMO BTT $(56.8 \%)$ were in this category $(P=.07)$. The median waitlist time was 7.5 days (range, 2-367 days) in the ECMO BTT group compared with 10 days (range, 1-102 days) in the non-BTT group $(P=.44)$.

All 12 patients were placed on ECMO with intent to transplant, all received an organ offer within 16 days of being placed on ECMO, and all successfully underwent transplantation during the study period, resulting in a BTT success rate of $100 \%$. Table 2 lists the characteristics of the 12 patients who received ECMO BTT. The median LAS in the ECMO BTT group was 83.7 (range, 34.691.2). Ten of the 12 patients in this group had pulmonary fibrosis (UNOS group D), 1 patient had cystic fibrosis, and 1 patient had antisynthetase syndrome (ECMO was used for acute fulminant exacerbation in this patient). A total of 8 of 12 patients $(66.7 \%)$ were on some form of invasive ventilator support at the time of listing for LTx, although evaluation for LTx had been started in all but $1 \mathrm{pa}-$ tient before initiation of ECMO. The patient with antisynthetase syndrome was transferred to our facility after being placed on ECMO elsewhere.

The median duration of ECMO support was 53 hours (range, 16-395 hours). A total of 11 of 12 patients (92\%) received VV ECMO for severe hypoxia, and 1 of 12 patients received VA ECMO for sudden cardiac arrest and high pulmonary artery pressures as previously mentioned. A bicaval dual-lumen catheter $(27 \mathrm{~F}$ or $31 \mathrm{~F}$; Avalon Elite) placed through the right internal jugular vein was used in 9 of 11 patients in the VV ECMO group (82\%); 2 of 11 patients in the VV ECMO group had internal jugular-femoral vein cannulation performed in the intensive care unit for more urgent ECMO. These were placed at the bedside because the patients were deemed too unstable for transport to the operating room. The sole patient placed on VA ECMO had femoral vein-femoral artery cannulation. A total of 7 of 12 patients $(58 \%)$ underwent concomitant tracheostomy at the time of ECMO initiation. Another 2 patients required tracheostomy post-transplant.

There were no deaths while on the ECMO circuit. A total of 3 of 12 patients $(25 \%)$ were awake with no sedation or light sedation, and 1 patient was able to transition to a chair at the bedside. No patients were able to ambulate while on ECMO during this period. The remaining 9 of 12 patients required continuous sedation because of agitation and air hunger, with resulting changes in flows on the ECMO circuit. Four patients in the ECMO BTT group $(33 \%)$ underwent LTx while on the ECMO circuit, whereas 8 patients were converted to CPB $(67 \%)$. ECMO or CPB was weaned at the conclusion of the transplant procedure in the operating room for all 12 patients, and all patients were decannulated at the end of the transplant procedure in the operating room. 
TABLE 1. Clinical characteristics of 93 patients with end-stage lung disease who underwent lung transplantation during the study period with and without extracorporeal membrane oxygenation as bridge to transplantation

\begin{tabular}{|c|c|c|c|c|}
\hline Variables* & Overall $(\mathbf{n}=\mathbf{9 3})$ & Non-BTT $(\mathrm{n}=\mathbf{8 1})$ & BTT $(n=12)$ & $P$ value $\dagger$ \\
\hline Median age at transplant, y (IQR) & $62(55-68)$ & $63(56-68)$ & $56(45.5-61)$ & .02 \\
\hline Sex, male, $n(\%)$ & $59(63.4)$ & $49(60.5)$ & $10(83.3)$ & .19 \\
\hline Race, $n(\%)$ & & & & .20 \\
\hline White & $71(76.3)$ & $62(76.5)$ & $9(75.0)$ & \\
\hline African American & $3(3.2)$ & $3(3.7)$ & $0(0)$ & \\
\hline Hispanic & $14(15.1)$ & $13(16.0)$ & $1(8.3)$ & \\
\hline Native American & $1(1.1)$ & $0(0)$ & $1(8.3)$ & \\
\hline Other & $4(4.3)$ & $5(3.7)$ & $1(8.3)$ & \\
\hline UNOS disease group, $\mathrm{n}(\%)$ & & & & .07 \\
\hline A & $27(29.0)$ & $26(32.1)$ & $1(8.3)$ & \\
\hline B & $2(2.2)$ & $2(2.5)$ & $0(0)$ & \\
\hline $\mathrm{C}$ & $4(4.3)$ & $3(3.7)$ & $1(8.3)$ & \\
\hline $\mathrm{D}$ & $55(59.1)$ & $45(55.6)$ & $10(83.3)$ & \\
\hline Redo LTx & $5(5.4)$ & $5(6.1)$ & $0(0)$ & \\
\hline Median pretransplant BMI, $\mathrm{kg} / \mathrm{m}^{2}(\mathrm{IQR})$ & $25(22.5-30)$ & $25(22.5-29.9)$ & $26.5(23.4-31.8)$ & .42 \\
\hline Median LAS (IQR) & $40.7(34.6-55.1)$ & $38.9(33.9-52.0)$ & $83.7(53.2-90.1)$ & $<.001$ \\
\hline Median Karnofsky score at listing (IQR) & $50(30-60)$ & $60(40-60)$ & $20(10-20)$ & $<.001$ \\
\hline Median systolic PAP (IQR) & $38(32-49)$ & $38(32-49)$ & $37.5(29-51)$ & .77 \\
\hline Median diastolic PAP (IQR) & $16(11-20)$ & $16(11-20)$ & $14.5(12-19.5)$ & .84 \\
\hline Mean PAP, median (IQR) & $25(21-32)$ & $25(21-32)$ & $28.5(23.5-34)$ & .32 \\
\hline Ventilated at listing, $\mathrm{n}(\%)$ & $13(13.9)$ & $5(6.2)$ & $8(66.7)$ & $<.001$ \\
\hline Median FEV1 at listing (IQR) & $34(22-51)$ & $36(21.5-51.5)$ & $33(25-47)$ & .79 \\
\hline Median FVC $\%$ at listing (IQR) & $49.5(38-66)$ & $50(39.5-68.5)$ & $37.5(21-46) \S$ & .01 \\
\hline Median days on waitlist (IQR) & $9(4-19)$ & $10(4-22)$ & $7.5(4.5-11)$ & .44 \\
\hline
\end{tabular}

$B T T$, Bridge to transplant; $I Q R$, interquartile range; UNOS, United Network for Organ Sharing; $L T x$, lung transplantation; $B M I$, body mass index; $L A S$, lung allocation score; $P A P$, pulmonary artery pressure; $F E V I$, forced expiratory volume in 1 second $\%$ predicted value; $F V C$, forced vital capacity $\%$ predicted value. *All continuous variables reported as median (interquartile range). $\dagger$ Wilcoxon rank-sum and Fisher exact were used to compare continuous and categoric variables, respectively. $\ddagger$ Group definition based on UNOS policy 10.1.F.i Lung disease diagnosis groups. §Data were missing for 2 patients who were too sick to undergo full pretransplant pulmonary testing.

Table 3 compares intraoperative characteristics and postoperative outcomes in the ECMO BTT and non-BTT groups. In both groups, most LTx procedures were double LTx (ECMO BTT: 100\%; non-BTT: 93\%). Intraoperative transfusions (both total and packed red blood cell) were higher in the ECMO BTT group $(P=.001, P<.001$, respectively), as were post-transplant packed red blood cell transfusions $(P=.05)$. A higher proportion of patients in the ECMO BTT group required return to the operating room than patients in the non-BTT group $(P=.02)$, mainly for secondary closure of open chest. Grade 3 primary graft dysfunction (per the standards set forth by the International Society of Heart and Lung Transplantation) at 48 to 72 hours post-transplant were comparable in both groups $(P=.72)$. Rates of delirium and critical illness myopathy were significantly higher in the BTT group $(P=.007, P<.001$, respectively). The ECMO BTT group had a higher number of bronchoscopies during the transplant stay.

A higher proportion of patients in the ECMO BTT group had venous thrombotic events during their hospital stays for
LTx $(\mathrm{n}=6 ; P=.03)$. One ECMO circuit thrombosis occurred as a result of low initial antithrombin (AT) levels $(39 \%)$; this required changing the circuit within the first 24 hours of ECMO initiation. All other venous thrombotic events in the ECMO BTT group were postoperative: Deep vein thrombosis (DVT) developed in 4 patients, and pulmonary embolism developed in 1 patient. Total and post-LTx length of hospital stay were both higher in the ECMO BTT group $(P<.001)$. There were no in-hospital deaths in the ECMO BTT group. Rates of pneumonia posttransplant were comparable between the 2 groups. A higher proportion of those in the ECMO BTT group required acute rehabilitation after discharge $(P=.001)$. However, functional status 1 year post-transplant was comparable between groups $(P=.74)$. Thirty-day, 90-day, and 1-year survivals were $100 \%, 100 \%$, and $100 \%$ in the ECMO BTT group and $98.8 \%, 97.5 \%$, and $91.3 \%$ in the non-BTT group, respectively $(P>.99)$. Kaplan-Meier survival estimates in both groups were similar $(\log$-rank $P=.24)$, as shown in Figure 2. 
Before 2015, 4 patients had been placed on ECMO at our center between 2011 and 2014. Our ECMO BTT success rate in the historical cohort was $75 \%(3 / 4)$, compared with $100 \%$ success rate in the 2015 ECMO BTT cohort. Functional status at listing for LTx was worse in the historical cohort (10 vs $20 ; P=.03$ ). The 2015 ECMO BTT group had better 1-year survival than the historical BTT cohort (log-rank $P=.04)$.

\section{DISCUSSION}

From 2011 to 2015, the overall rate of ECMO BTT at our institution was $4.7 \%(16 / 334)$ in our transplant program. This is higher than reported ECMO pretransplant rates from national registry studies, which have been reported to range from $0.6 \%$ to $3.5 \%{ }^{1,14}$ At our center, the use of ECMO as BTT has increased 3-fold from 1.6\% (4/241) between 2011 and 2014 to $12.9 \%$ (12/93) in 2015. The most likely reason for this upswing - aside from our increase in transplant volume and patients referred in later stages of their fibrotic disease state-is the institution of an intensive ECMO education program and updated technology. Our patients receiving ECMO BTT were younger than patients not receiving BTT, with high acuity (demonstrated by higher LAS and lower functional status at the time of listing). This trend is consistent with reports from UNOS-based studies $^{1,14,15}$ and with single-center studies in the United States. ${ }^{6,7}$

Rates of mechanical ventilation pretransplant and CPB use during transplant were higher in the ECMO BTT group, which is consistent with single-center reports from the United States ${ }^{7}$ and Europe. ${ }^{12}$ Since the first patient was placed on ECMO at our institution in 2011, practitioners in our program carried out a total of 16 ECMO BTT cannulations by December 2015, with 15 successful "bridges to transplant" (a rate of $93.7 \%$ ), which is higher than previously reported rates, which range from $46 \%$ to $89 \%, 5,7,9,10,12,20-27$ as well as 1-year survival of $100 \%$, which is consistent with the range of $62 \%$ to $100 \%$ reported rates from other single-center studies. ${ }^{6-8,10,21-23,27,28}$ The patients who were salvaged using ECMO as BTT all had overall excellent functional status at 1 year, which to date has not been reported in the literature.

\section{Specialized Extracorporeal Membrane Oxygenation Program}

We have gained valuable experience since our first successful use of ECMO as BTT, and have since refined our clinical practice and decision-making processes. This retrospective review describes our results using ECMO as BTT after implementation of a multidisciplinary ECMO program that uses modern ECMO devices and cannulas. Development of a comprehensive ECMO program is a complex, multifaceted undertaking that requires collaboration from different departments. ${ }^{6,14}$ Successfully restructuring our ECMO program meant upgrading equipment, changing infrastructure, continuously educating our clinicians, and establishing clear and easy communication between bedside staff and physicians. Although it is optimal to place patients who are already on the transplant waitlist on ECMO in the transplant hospital, it is feasible to transport LTx candidates who are already on ECMO should they experience respiratory failure outside the transplant center. ${ }^{29}$ One patient in this study (patient 12) was placed on ECMO at a sister facility and was

TABLE 2. Characteristics of patients who underwent lung transplantation with extracorporeal membrane oxygenation as bridge to transplantation in 2015

\begin{tabular}{|c|c|c|c|c|c|c|}
\hline Patient & Age, $y$ & Diagnosis & LAS & ECMO duration, $h$ & LOS after LTx, d & $\begin{array}{l}\text { Post-LTx Karnofsky scale } \\
\text { functional status score }\end{array}$ \\
\hline 1 & 51 & IPF & 90 & 57 & 33 & 90 \\
\hline 2 & 51 & $\mathrm{IPF} / \mathrm{PH}$ & 90 & 45 & 16 & 90 \\
\hline 3 & 25 & $\mathrm{CF}$ & 90 & 166 & 30 & 90 \\
\hline 4 & 58 & IPF & 87 & 107 & 16 & 90 \\
\hline 5 & 23 & IPF & 43 & 247 & 26 & 90 \\
\hline 6 & 68 & IPF & 89 & 38 & 44 & 70 \\
\hline $7 \dagger$ & 59 & IPF & 61 & 16 & 100 & 80 \\
\hline 8 & 57 & IPF & 50 & 18 & 27 & 90 \\
\hline 9 & 55 & IPF & 88 & 49 & 23 & 90 \\
\hline 10 & 66 & IPF & 67 & 27 & 18 & 80 \\
\hline 11 & 63 & IPF & 86 & 78 & 14 & 90 \\
\hline 12 & 41 & Antisynthetase syndrome & 43 & 395 & 20 & 100 \\
\hline
\end{tabular}

$L A S$, Lung allocation score; $E C M O$, extracorporeal membrane oxygenation; $L O S$, length of stay; $L T x$, lung transplantation; $I P F$, idiopathic pulmonary fibrosis; $P H$, pulmonary hypertension; $C F$, cystic fibrosis. *Score of 50-70 on the Karnofsy Performance Status (KPS) Scale signifies inability to work, but living at home and able to care for most personal needs. Score of 80-100 signifies ability to carry out normal activity and work with no assistance needed. †Of the 12 patients in this study, this patient was the only patient who underwent venoarterial ECMO instead of venovenous ECMO. 
TABLE 3. Perioperative and postoperative complications in patients who underwent lung transplantation between January 1, 2015, and December 31, 2015, with or without bridge to transplantation with extracorporeal membrane oxygenation

\begin{tabular}{|c|c|c|c|c|}
\hline Variables* & Overall $(\mathbf{n}=\mathbf{9 3})$ & Non-BTT $(\mathbf{n}=81)$ & BTT $(\mathbf{n}=12)$ & $P$ value \\
\hline Double LTx, n (\%) & $90(96.7)$ & $78(96.3)$ & $12(100.0)$ & $>.99$ \\
\hline CPB usage, $\mathrm{n}(\%)$ & $23(24.7)$ & $15(15.8)$ & $8(66.6) \ddagger$ & .001 \\
\hline First lung ischemic time, median (IQR) & $229(195-257)$ & $229(197-258)$ & $237(123.5-247.5)$ & .37 \\
\hline Second lung ischemic time, median (IQR) $\S$ & $287(255-323)$ & $289.5(258-334)$ & $259(176-313.5)$ & .11 \\
\hline PGD grade 3 at $48-72 \mathrm{~h}, \mathrm{n}(\%)$ & $25(26.9)$ & $21(25.9)$ & $4(33.3)$ & .72 \\
\hline ECMO for PGD, $\mathrm{n}(\%)$ & $2(2.2)$ & $2(2.5)$ & $0(0)$ & $>.99$ \\
\hline Intraoperative PRBC transfusion, median (IQR) & $3(1-5)$ & $2(1-4)$ & $6(3.5-9)$ & $<.001$ \\
\hline Intraoperative total blood products transfusions, median (IQR) & $4(1-15)$ & $3(1-12)$ & $24.5(6-29)$ & .001 \\
\hline Postoperative PRBC transfusion, median (IQR) & $1(0-3)$ & $1(0-2)$ & $2.5(0.5-8)$ & .05 \\
\hline Return to OR, n (\%) & $21(22.6)$ & $13(16.1)$ & $8(66.7)$ & .001 \\
\hline Reintubation post-transplant, $\mathrm{n}(\%)$ & $6(6.5)$ & $5(6.2)$ & $1(9.3)$ & .57 \\
\hline Tracheostomy post-transplant, $\mathrm{n}(\%)$ & $8(8.6)$ & $6(7.4)$ & $2(16.7)$ & .27 \\
\hline Pneumonia, n (\%) & $11(11.8)$ & $9(11.1)$ & $2(16.7)$ & .63 \\
\hline Post-transplant bronchoscopies during hospital stay, median (IQR) & $3(2-4)$ & $3(2-4)$ & $3.5(3-6)$ & .04 \\
\hline Total LOS, median (IQR) & $17(11-30)$ & $15(11-26)$ & $39(32.5-50.5)$ & $<.001$ \\
\hline Post-transplant LOS, median (IQR) & $15(10-19)$ & $13(10-17)$ & $25(18-31)$ & $<.001$ \\
\hline 30-d mortality, n (\%) & $1(1.1)$ & $1(1.2)$ & $0(0)$ & $>.99$ \\
\hline Disposition at discharge, $\mathrm{n}(\%)$ & & & & .001 \\
\hline Home & $59(63.4)$ & $57(70.4)$ & $2(16.7)$ & \\
\hline IPR/SNF & $34(36.6)$ & $24(29.6)$ & $10(93.3)$ & \\
\hline Delirium, n (\%) & $17(18.3)$ & $11(13.5)$ & $6(50)$ & .01 \\
\hline Myopathy, n (\%) & $20(21.5)$ & $10(12.3)$ & $10(83.3)$ & $<.001$ \\
\hline Thrombotic event, n (\%) & $21(22.6)$ & $15(18.5)$ & $6(50)$ & .03 \\
\hline Survival at $1 \mathrm{y}, \mathrm{n}(\%)$ & $85 / 92(92.4)$ & $73 / 80(91.3)$ & $12 / 12(100)$ & 1.0 \\
\hline
\end{tabular}

$\overline{B T T}$, Bridge to transplant; $L T x$, lung transplantation; $C P B$, cardiopulmonary bypass; $I Q R$, interquartile range; $P G D$, primary graft dysfunction; $E C M O$, extracorporeal membrane oxygenation; $P R B C$, packed red blood cells; $O R$, operating room; $L O S$, length of stay; $I P R$, inpatient rehabilitation; $S N F$, skilled nursing facility. *All continuous variables reported as median (IQR). †Wilcoxon rank-sum and Fisher exact tests were used to compare continuous and categoric variables, respectively. $\ddagger$ Transitioned to CPB during transplant; remaining 4 of 12 transplants were performed on ECMO. §For double LTx cases.

transferred to our center for further management and, ultimately, LTx.

\section{Length of Stay}

Although the patients in our study experienced good outcomes, ECMO as BTT was associated with longer length of stay and a greater need for rehabilitation. The patients in this study who required ECMO as BTT were more critically ill (confirmed by their higher LAS scores) and were bedbound at the time of ECMO initiation, so prolonged recovery was anticipated. We evaluated each patient's rehabilitation potential before their conditions worsened and necessitated ECMO; however, acuity of illness, ECMO duration, immobility, and sedation all exacerbate the functional decline that affects rehabilitation potential. Fortunately, the waitlist times at our center are relatively short, which helped minimize ECMO duration. This may not be the case in all regions of the country, and other programs should consider patients' expected waitlist time before placing patients on ECMO as BTT. ${ }^{17,24}$

\section{Extracorporeal Membrane Oxygenation-Related Complications}

Delirium is a serious event in critically ill patients that is often associated with pain management and sedation. ${ }^{30} \mathrm{We}$ have tried to minimize sedation and to use shorter-acting agents for sedation (eg, propofol or remifentanil), but air hunger and agitation that affect circuit flows and cannula positioning have necessitated sedation for most of our patients. Protocols and guidelines focusing on delirium prevention would likely improve outcomes in our ECMO as BTT cases and is an ongoing effort at our institution. Myopathy has been a major post-transplant complication in the ECMO as BTT group. Factors that may contribute to this morbidity include bedbound status, prolonged hospital stay, and acute exacerbation of disease process, which requires administration of high-dose steroids. ${ }^{18}$ Myopathy will likely remain a problem in these patients, but active engagement of each patient in physical therapy and ambulation (if possible) may help lessen the degree of critical illness myopathy. Earlier institution of ECMO (ie, before 


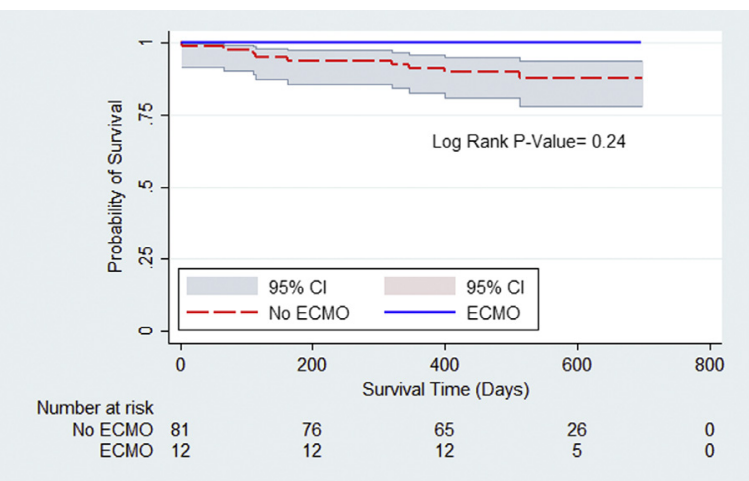

FIGURE 2. Kaplan-Meier survival estimates by ECMO use as bridge to LTx during the study period. $C I$, Confidence interval; ECMO, extracorporeal membrane oxygenation. Used with permission from Norton Thoracic Institute, Phoenix, Arizona.

patients have critically deteriorated) may facilitate ambulation in these patients. ${ }^{8} \mathrm{We}$ are in the process of educating our intensive care unit personnel and ancillary staff on the importance and feasibility of ambulation while on ECMO. In the meantime, our center continues to aggressively recruit donor lungs to expand the organ pool, decreases postoperative ventilator times with scheduled bronchoscopy, and refers patients to acute rehabilitation after discharge for conditioning exercises.

In an effort to encourage active participation in physical therapy, we avoid femoral cannulation unless it must be used on an emergency basis. Stable patients are taken to the operating room, where VV ECMO is deployed using both fluoroscopy and transesophageal echocardiography with a dual-lumen internal jugular cannula. Tracheostomy can facilitate ventilator weaning and patient activity, ${ }^{8}$ and was performed in 7 of 12 of our ECMO cases at the time of ECMO initiation with no tracheostomy-related complications. Emergency cannulation at the bedside using the internal jugular vein as inflow and the femoral vein as outflow can be performed in patients who cannot tolerate transport to the operating room.

Because of the greater need for blood transfusion during and after transplant and the higher rates of thrombosis associated with ECMO, we continue to modify our ECMO coagulation management. Hemostasis management encompasses the traditional coagulation markers, but attention to D-dimer, AT, Protein C, and Protein S are particularly important. D-dimer evaluation can detect clot degradation, fibrin split products, and reduction of clot stability. AT, Protein $\mathrm{C}$, and Protein $\mathrm{S}$ are natural anticoagulants, but deficiency of any of these could promote a procoagulant state. Pulmonary embolus and DVT continue to be postoperative concerns, especially because steroid use and perioperative immobility increase the risk of thrombosis. DVT prophylaxis in the perioperative period remains very important. We were able to decannulate all patients after the transplant procedure in the operating room, which allowed for reversal of anticoagulation and minimized further bleeding risk postimplantation. Some centers have reported the use of ECMO post-transplant to treat primary graft dysfunction or pulmonary hypertension, ${ }^{31,32}$ but this was not necessary for any of the patients in our cohort.

\section{Other Considerations}

No difference was observed in rates of grade 3 primary graft dysfunction at 48 to 72 hours of transplant between ECMO BTT and non-BTT groups. Although this is consistent with rates reported by the Lung Transplant Outcomes Group, ${ }^{31}$ the true effect of ECMO as BTT on development of chronic rejection has not yet been studied. We will continue to monitor the patients we treated with ECMO as BTT for long-term survival and incidence of chronic allograft dysfunction, and intend to report those findings at a later date.

\section{Study Limitations}

This study is subject to the limitations associated with any retrospective, single-center review. Because of the relatively small numbers in our sample, our data lack statistical power to conduct a meaningful multivariable analysis adjusting for differences in baseline characteristics including higher acuity of our ECMO BTT group, whether patients were ventilated at the time of listing, and disposition at discharge compared with the non-BTT group. Consequently, the stand-alone effect of ECMO as BTT on LTx outcomes or the impact of various known risk factors (eg, higher LAS or greater patient age) is difficult to ascertain from our existing data. Long-term outcomes in both groups are lacking, although they are being prospectively studied. There is a need for further prospective, multicenter studies that would assess the effects of ECMO use pretransplant.

\section{CONCLUSIONS}

Our success with ECMO as BTT is similar to reports from other centers, ${ }^{6,7}$ and reported outcomes of those with ECMO BTT who undergo LTx at high-volume centers have been comparable to those who undergo non-BTT LTx. ${ }^{14,15}$ Our positive outcomes were due in large part to the education of our staff on the ECMO devices and processes, improved clinical infrastructure surrounding ECMO use, and upgraded models of ECMO machines. Our study adds to the literature because it illustrates what can be accomplished through a dedicated ECMO program, and because the 1-year functional status of patients bridged to transplant with ECMO is rarely reported. 
The use of ECMO as BTT needs to be better defined as a part of the global algorithm in the care of patients with endstage lung disease. Myopathy and delirium remain serious complications at our center, and more attention to ECMO timing and duration, sedation, and steroid doses may be warranted. Other complications, such as DVTs and bleeding, may be remedied by upgrading of our coagulation instrumentation to the thromboelastogram to allow faster evaluation of coagulopathy. Further evaluation and study of the coagulation panel in the post-ECMO/posttransplant phase may offer more insight into the high number of thrombotic complications, although this seems to be a problem commonly seen at other centers. Although no excessive severe primary graft dysfunction was evident in this patient cohort, it remains to be seen whether rejection, incidence of bronchiolitis obliterans syndrome, and overall survival are affected in patients who receive ECMO as BTT in the new era.

\section{Conflict of Interest Statement}

Authors have nothing to disclose with regard to commercial support.

The authors thank Clare Prendergast, who provided editorial assistance for this article.

\section{References}

1. George TJ, Beaty CA, Kilic A, Shah PD, Merlo CA, Shah AS. Outcomes and temporal trends among high-risk patients after lung transplantation in the United States. J Heart Lung Transplant. 2012;31:1182-91.

2. Yusen RD, Edwards LB, Kucheryavaya AY, Benden C, Dipchand AI, Dobbels F, et al. The Registry of the International Society for Heart and Lung Transplantation: Thirty-First Adult Lung and Heart-Lung Transplant Report-2015; Focus Theme: Early Graft Failure. J Heart Lung Transplant. 2015;34:1264-77.

3. Singer JP, Blanc PD, Hoopes C, Golden JA, Koff JL, Leard LE, et al. The impact of pre-transplant mechanical ventilation on short- and long-term survival after lung transplantation. Am J Transplant. 2011;11:2197-204.

4. Gottlieb J, Warnecke G, Hadem J, Dierich M, Wiesner O, Fühner T, et al. Outcome of critically ill lung transplant candidates on invasive respiratory support. Intensive Care Med. 2012;38:968-75.

5. Lang G, Taghavi S, Aigner C, Renyi-Vamos F, Jaksch P, Augustin V, et al. Primary lung transplantation after bridge with extracorporeal membrane oxygenation: a plea for a shift in our paradigms for indications. Transplantation. 2012; 93:729-36.

6. Hoopes CW, Kukreja J, Golden J, Davenport DL, Diaz-Guzman E, Zwischenberger JB. Extracorporeal membrane oxygenation as a bridge to pulmonary transplantation. J Thorac Cardiovasc Surg. 2013;145:862-8.

7. Toyoda Y, Bhama JK, Shigemura N, Zaldonis D, Pilewski J, Crespo M, et al. Efficacy of extracorporeal membrane oxygenation as s bridge to lung transplantation. J Thorac Cardiovasc Surg. 2013;145:1065-71.

8. Rehder KJ, Turner DA, Hartwig MG, Williford WL, Bonadonna D, Walczak RJ Jr, et al. Active rehabilitation during extracorporeal membrane oxygenation as a bridge to lung transplantation. Respir Care. 2013;58:1291-8.

9. Shafii A, Mason DP, Brown CR, Vakil N, Johnston DR, Mccurry KR, et al. Growing experience with extracorporeal membrane oxygenation as a bridge to lung transplantation. ASAIO J. 2012;8:526-9.

10. Javidfar J, Brodie D, Iribarne A, Jurado J, LaVelle M, Brenner K, et al. Extracorporeal membrane oxygenation as a bridge to lung transplantation and recovery. $J$ Thorac Cardiovasc Surg. 2012;144:716-21.

11. Abrams D, Javidfar J, Farrand E, Mongero LB, Agerstrand CL, Ryan P, et al. Early mobilization of patients receiving extracorporeal membrane oxygenation: a retrospective cohort study. Crit Care. 2014;18:R38.
12. Inci I, Klinzing S, Schneiter D, Schuepbach RA, Kestenholz P, Hillinger S, et al. Outcome of extracorporeal membrane oxygenation as a bridge to lung transplantation: an institutional experience and literature review. Transplantation. 2015; 99:1667-71.

13. Mason DP, Thuita L, Nowicki ER, Murthy SC, Pettersson GB, Blackstone EH. Should lung transplantation be performed for patients on mechanical respiratory support? The US experience. J Thorac Cardiovasc Surg. 2010;139:765-73.

14. Hayes D Jr, Tobias JD, Tumin D. Center volume and extracorporeal membrane oxygenation support at lung transplantation in the Lung Allocation Score Era. Am J Respir Crit Care Med. 2016;194:317-26.

15. Hayanga AJ, Aboagye J, Esper S, Shigemura N, Bermudez CA, D'Cunha J, et al. Extracorporeal membrane oxygenation as a bridge to lung transplantation in the United States: an evolving strategy in the management of rapidly advancing pulmonary disease. J Thorac Cardiovasc Surg. 2015;149:291-6.

16. Iribarne A, Russo MJ, Davies RR, Hong KN, Gelijns AC, Bacchetta MD, et al. Despite decreased wait-list times for lung transplantation, lung allocation scores continue to increase. Chest. 2009;135:923-8.

17. Valapour M, Skeans MA, Smith JM, Edwards LB, Cherikh WS, Callahan ER, et al. OPTN/SRTR Annual data report 2014: Lung. Am J Transplant. 2016; 16(S2):141-68

18. Tabarki B, Coffinieres A, Van den Bergh P, Huault G, Landrieu P, Sebire G. Critical illness neuromuscular disease: clinical, electrophysiological, and prognostic aspects. Arch Dis Child. 2002;86:103-7.

19. Policy 10 Allocation of Lungs. Organ Procurement and transplantation network (OPTN) policies. Available at: https://optn.transplant.hrsa.gov/media/1200/ optn_policies.pdf\#nameddest=Policy_10. Accessed September 1, 2016.

20. Tudzinski FC, Kaestner F, Schafers H-J, Fandrich S, Seiler F, Bohmer P, et al. Outcome of patients with interstitial lung disease treated with extracorporeal membrane oxygenation for acute respiratory failure. Am J Respir Crit Care Med. 2016;193:527-33.

21. Dellgren G, Riise GC, Sward K, Gilljam M, Rexius H, Liden H, et al. Extracorporeal membrane oxygenation as a bridge to lung transplantation: a long term study. Eur J Cardiothorac Surg. 2015;47:95-100.

22. Lafarge M, Mordant P, Thabut G, Brouchet L, Falcoz P-E, Haloun A, et al. Experience of extracorporeal membrane oxygenation as a bridge to lung transplantation in France. J Heart Lung Transplant. 2013;32:905-13.

23. Anile M, Diso D, Russo E, Patella M, Carillo C, Pecoraro Y, et al. Extracorporeal membrane oxygenation as bridge to lung transplantation. Transplant Proc. 2013; 45:2621-3.

24. Crotti S, Iotti GA, Lissoni A, Belliato M, Zanierato M, Chierichetti M, et al. Organ allocation waiting time during extracorporeal bridge to transplant affects outcomes. Chest. 2013;144:1018-25.

25. Fuehner T, Kuehn C, Hadem J, Wiesner O, Gottlieb J, Tudorache I, et al. Extracorporeal membrane oxygenation in awake patients as bridge to lung transplantation. Am J Respir Crit Care Med. 2012;185:763-8.

26. Weig T, Irlbeck M, Frey L, Zwibler B, Winter H, Perissler G, et al. Parameters associated with short- and midterm survival in bridging to lung transplantation with extracorporeal membrane oxygenation. Clin Transplant. 2013;27:E563-70.

27. Hammainen P, Schersten H, Lemstrom K, Riise GC, Kukkone S, Sward K, et al. Usefulness of extracorporeal membrane oxygenation as a bridge to lung transplantation: a descriptive study. J Heart Lung Transplant. 2011; 30:103-7.

28. Mohite PN, Sabashnikov A, Reed A, Saez DG, Patil NP, Popov A-F, et al. Extracorporeal life support in "awake" patients as a bridge to lung transplant. J Thorac Cardiovasc Surg. 2015;63:699-705

29. Lee SG, Son BS, Kang PJ, Cho WH, Kim DH, Lee YS, et al. The feasibility of extracorporeal membrane oxygenation support for inter-hospital transport and as a bridge to lung transplantation. Ann Thorac Cardiovasc Surg. 2014;20:26-31.

30. Reade MC, Finfer S. Sedation and delirium in the intensive care unit. $N$ Engl J Med. 2014;370:444-54.

31. Fischer S, Bohn D, Rycus P, Pierre AF, de Perrot M, Waddell TK, et al. Extracorporeal membrane oxygenation for primary graft dysfunction after lung transplantation: analysis of the Extracorporeal Life Support Organization (ELSO) registry. J Heart Lung Transplant. 2007;26:472-7.

32. Pereszlenyi A, Lang G, Steltzer H, Hetz H, Kocher A, Neuhauser P, et al. Bilateral lung transplantation with intra- and postoperatively prolonged ECMO support in patients with pulmonary hypertension. Eur J Cardiothorac Surg. 2002; 21:858-63. 
Key Words: extracorporeal membrane oxygenation, lung transplantation

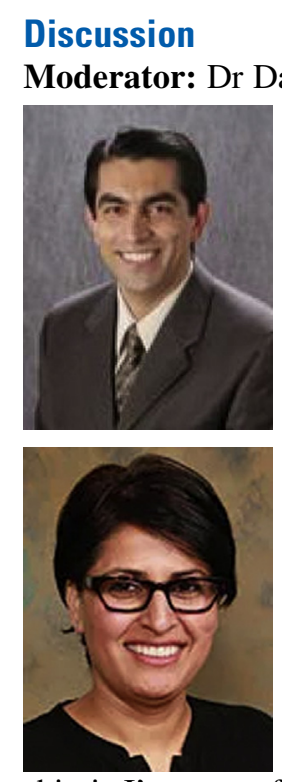

Presenter: Dr Samad Hashimi (for Dr Emily Todd)

Discussant: Dr Jasleen Kukreja Dr Cook. We're going to push forward. Our next presentation is from Dr Todd et al, and it's "Extracorporeal Membrane Oxygenation as a Bridge to Lung Transplantation: More Successful in the Present Era."

Dr Hashimi. My name is Samad Hashimi. I'm one of the thoracic surgeons of the Northern Thoracic Institute. I'm here to present our recent article on ECMO used as a bridge to LTx. We want to thank the Society for accepting the article and giving us the opportunity to present. We present a video-assisted thoracoscopic surgery training course for Ethicon (Somerville, NJ), but with relation to this talk, we don't have any conflicts. ECMO has been used to bridge patients for cardiopulmonary support for a long time, but over the last decade it is being used more as a way to bridge patients to LTx. The technology obviously has gotten better, and the circuits are smaller. The Avalon dual cannulation has made VV ECMO easier, made it more possible to essentially mobilize patients, and made it safer to deploy earlier. The outcomes, unfortunately, are a bit controversial, and they depend on the center and volume. In the big scheme, ours is a new program, and we've gone through our own growing pains. We've had to develop not only a transplant center but also an ECMO program. As time has gone on, we've become one of the busiest programs in the country, so we looked at our data between January 2015 and December 2015, and our ECMO cases and the complications in survival for all those patients. To develop the program obviously requires a lot of work. It requires a lot of education involving courses and training the physicians, perfusionists, nurses, and respiratory therapists. It's a multidisciplinary team approach. The circuits, the cannulas, and getting the hospital to have a buy-in took a lot of work. It requires constant communication between different teams. During that time period, we performed 93 LTxs. We were able to bridge to transplant in 12 of those patients. The majority of the patients had pulmonary fibrosis. One patient had cystic fibrosis, and 1 patient acutely deteriorated from their antisynthetase syndrome. Our preferred modality for cannulation, for VV ECMO, was always a dual-lumen cannulation if we could, and obviously if they needed VA it was an extra cannulation, with the goals of these patients participating in physical therapy and being more mobile. We transported 1 patient from our sister facility. It essentially takes a village to transfer a patient and a lot of effort not only from the administration but also from physicians and nurses. So these are our results. The average age for patients receiving ECMO was 51 years. The LAS score is 73 , and that's lower than what it should be because in 4 of those patients, when we met them, they were already intubated and we could not get a 6-minute walk, so their LAS scores were technically higher. The average duration of ECMO is 103 hours, and their length of stay after LTx, which was also longer than in our typical patients, was approximately 30 days. The biggest complication was 1 circuit that acutely clotted within 24 hours. Four patients had a DVT within 3 months after transplant, and 1 patient had a pulmonary embolism. When we went back and looked at those patients, we noticed that they had low AT-III levels, especially the one with the clotted circuit, and since that time, we've adjusted our protocol and check the patients before induction. If it's an emergency cannulation, then we add AT-III to the circuit and check it every 24 hours. Other problems that obviously come with ECMO is bleeding. The biggest bleeding sites are the cannulation sites and tracheostomy sites. One patient had an almost catastrophic bleed from a percutaneous gastrostomy tube site. We used to be fairly cavalier about using percutaneous gastrostomy, but currently we try to feed them through a mesoduodenal tube until they're done. So unfortunately, we weren't able to ambulate any of our patients. We've started to this year, and this is something we're still struggling with. All of the 12 patients survived the transplantation; 3 underwent transplantation on ECMO, and 9 had to be converted to $\mathrm{CPB}$. All of them were weaned at the end of the case. Table 1 compares the ECMO group with the non-ECMO group. The average age of patients is approximately 56 years, the majority of them were male, and all of them survived transplantation. Eight of the 12 patients had to return to the operating room, and this was actually intentional. We left them open, only 1 patient had any bleeding issues, but in the remainder, we left them open for a second look. None of them had any wound complications. The biggest problems that we had were myopathy and delirium. To some degree, it's understandable. These patients are sick and bedridden for a long time, which explains their longer length of stay in the hospital. All of them survived, 9 of those patients have reached their 1-year survival, and the remainder of them are fairly active, and that's based on their functional scores. They're all scoring between 80 and 100, which means they can do all activities of daily living 
without any help and they can actually work. Approximately 3 of the 12 patients had a primary graft dysfunction grade of 3 . We still have to figure out what the long-term implication of that is, but this number is on par with the national average, too. In summary, this is a retrospective evaluation from a single center, so obviously it has limitations based on that. But what we have been able to show is that you can salvage very sick patients. We had $100 \%$ of the patients who survived the transplantation. All of them were discharged and ultimately to their homes. They have an increased length of stay, and the biggest problems we had were myopathy and thrombosis. We need to get better at it and study that further. The functional status of all these patients is excellent so far. We still have to see what their long-term outcomes are, and hopefully we can look at that over the next 3 to 5 years. With intensive education programs and the latest technology, it is possible to salvage a very sick group of patients, but unfortunately the length of stay is longer than the average. We are still working on trying to get an ambulatory ECMO program, and we're learning from our mistakes. With each patient, you have to learn some new things every time so we were able to get our first ambulatory ECMO case this year, but we're not there yet, so we're hoping to get better as time goes on.

Dr Cook. Dr Kukreja will start off our discussion.

Dr Kukreja. I want to congratulate the group at St Joe's for excellent outcomes. The patient underscores the need for a multidisciplinary approach as you pointed out and the equation of the entire team. Your 12 patients last year had $100 \%$ survival after transplant. This is the only article I know that has shown $100 \%$ efficacy. Some of the smaller series, for instance, the one from Columbia, showed $100 \%$ 1 -year survival, but their efficacy was only $55 \%$ and only 10 of 18 patients made it to transplantation. In our own series, we've been performing ECMO bridge to transplant for about a decade, and our success has been only $88 \%$ bridging to transplant and our 1-year survival was $93 \%$, so congratulations.

Dr Kukreja. I have 3 questions. Outcomes obviously depend to a great degree on the judgment of the treatment team in terms of who you select to put on ECMO as well as timing of ECMO. Would you like to share with us what your algorithm was?

Dr Hashimi. To some degree, we've obviously learned from our prior mistakes. It's a bit of a multidisciplinary approach; obviously each patient is evaluated, not only by our pulmonologists and surgeons. The biggest thing we try to look at is their functional status before we put them on ECMO. Obviously, if somebody has been bedridden for months ahead of time, we know that the chance of recovery is not as great. If they're older and have multiple organ failures, we're not going to put those patients on ECMO and hope we can get them to a transplant. So age and functional status become important factors. We keep harping at their functional status over and over and what they were doing within the last few weeks to months. Early on, we did make mistakes as far as putting patients on ECMO without knowing about their social backgrounds and what their resources were beforehand, and we learned the hard way, so getting a good social assessment is also important. It's always nicer if we know the patients, but like I showed, we had 4 of those patients who at the time we met them were already intubated. So to some degree, it's everybody's gut feeling, but it has to be individual groups, so pulmonologists, social workers, and surgeons meet individually, and everybody has to have buy-in into that patient, so, unfortunately we are going to fail every now and then.

Dr Kukreja. For instance, how many patients were already intubated, paralyzed, and sedated?

Dr Hashimi. Three, actually 4 of those patients, by the time we met them, they were already intubated. The patient who we transferred from the sister facility decompensated within the previous 2 weeks, so we transferred the patient. We put the patient on ECMO and transferred the patient. The remainder of them were going to be listed or we had some knowledge beforehand before they basically deteriorated. By the time 3 of the patients were referred, they were already intubated, so we had to be careful with those patients, but they were fairly active within the previous month. Somebody knew that they were walking within the previous month, so that became kind of important for us.

Dr Kukreja. The next question relates to the rate of myopathy. It struck me that you mentioned $83 \%$ had critical myopathy. Given the fact that the range you have, patients on ECMO, the majority, more than $75 \%$ of your patients, were on ECMO for less than 5 days.

Dr Hashimi. Right.

Dr Kukreja. The degree of myopathy is profound. First, how did you define myopathy and can you explain why within 5 days somebody would develop that.

Dr Hashimi. Well, to some degree. We had a couple of people who were on ECMO a long time because we couldn't find them an organ, but we don't have, as a general rule, a long waitlist for our transplant program. Patients don't have to wait a long time unless they have a high panel-reactive antibody or something else that keeps them on the waitlist. Despite that, once they were on ECMO, they were on steroids. If we couldn't mobilize them, it took a long time to get them mobilized. So it was basically how they participated with physical therapy. With all the steroids and everything else, it was a challenge to get them mobilized.

Dr Kukreja. So that goes back to my first question. It would be important to know how many days in terms of timing of ECMO deployment was the patient already intubated/paralyzed.

Dr Hashimi. Right.

Dr Kukreja. Given the short duration on ECMO, the degree of weakness seems a bit high. 
Dr Hashimi. It seems long.

Dr Kukreja. Yes.

Dr Hashimi. I'll have to look back at how long each patient was intubated or bedridden beforehand. To be honest with you. I don't remember that off the top of my head.

Dr Kukreja. Survival obviously depends on our ability to procure organs, and you alluded to the fact that in your program, the waitlist is not long because your patients don't wait on the list very long, because you're in a fortunate situation of performing transplants in them very quickly. What is the average duration of your waitlist in terms of waiting time on the list?

Dr Hashimi. Usually within a few weeks. We've had patients who have been listed in the morning and underwent transplantation at night, but that doesn't happen too often. The longest we've had anybody wait on the list was 2 years ago. We had a hard time finding an organ (1 year), but that doesn't happen too often. The average is probably a couple of weeks to 1 month. When patients come in for an evaluation, the biggest thing that they go through, the longest time they have to wait, is to finish all their workup. Their workup sometimes takes longer than their wait time on the list.

Dr Kukreja. Our wait time can be anywhere from 6 months to 1 year because we have a lot of competition in our zone. The second part of that question is, I think you pretty much answered this. You probably don't have any waitlist mortality.

Dr Hashimi. We don't. In the last 5 years, I think we had 1 patient who died on the list. We don't have much of a waitlist mortality.

Dr Kukreja. In the country, including our center, the waitlist mortality is $15 \%$ to $20 \%$, so that again goes to the fact that you are in a unique situation geographically speaking.

Dr Hashimi. We have to give a lot of credit to our pulmonologists, because they do a great job of managing the donors. They manage donors ahead of time, and essentially, it's a way of in vivo perfusion as opposed to ex vivo perfusion for organs. They do a lot of work beforehand, so we have to give them a lot of credit for that.

Dr Kukreja. What is your local organ procurement organization's lung recovery rate?

Dr Hashimi. I don't know. Most of the organs come from other states. The majority don't come from Arizona itself, although our hospital is one of the busiest from an organ procurement organization standpoint, but we don't get a lot of lungs from our own hospital. We mainly get them from California, Colorado, New Mexico, and Texas, so the surrounding regions.

Dr Cook. Dr Mokadam?

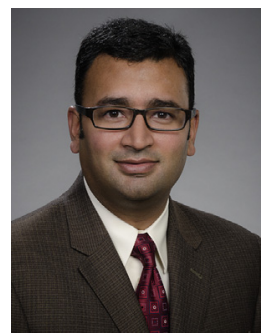

Dr Mokadam. I know Mike Mulligan is gone, so I will represent the LTx program from UW for a minute. Excellent results and really remarkable work you've accomplished there. Some of the questions that I had you've already answered, most importantly that you have very short waiting times. Having an average ECMO time to transplant of 100 hours is remarkable and unseen anywhere else. Do you alter your immunosuppression regimen with your degree of myopathy that you're seeing or are you considering something along those lines to try to reduce your myopathic rates?

Dr Hashimi. We have talked about that. I think that's something we're looking into right now.

Dr Mokadam. Because I don't want to take the effort to delete your name from the slide, you can go ahead and ask your question.

Dr Adel. It will be quick. I've had the opportunity to be a part of BTT ECMO programs now in 2 different institutions, and we've had similar experience with difficulty actually getting patients ambulating, as you have experienced. I wonder if you could just briefly comment on what you've seen as the barriers and what solutions you're enacting.

Dr Hashimi. From this patient cohort, what we realize, and this is just my personal bias, if you know the patient beforehand, it takes a lot of education of one, when a patient bucks on the circuit and the nurses kind of freak out, then the first instinct is to sedate them again. So education is a big part of it, but another part of it is also the patient itself. Patients who become anxious easily don't do very well. The patient who went home within 14 days, after he was on ECMO and went home within a couple of weeks, he was motivated beforehand, so patient selection becomes important. If you know the patient ahead of time, that's important. But a lot of it has to do with who is managing the patient, who's at the bedside, how you're going to sedate him, and what you're going to use. We haven't really figured that out to be honest with you, but we're working on that. 